\title{
In vivo hepatogenic capacity and therapeutic potential of stem cells from human exfoliated deciduous teeth in liver fibrosis in mice
}

Takayoshi Yamaza ${ }^{1 \dagger}$, Fatima Safira Alatas ${ }^{2 \dagger}$, Ratih Yuniartha ${ }^{2}$, Haruyoshi Yamaza ${ }^{3}$, Junko K. Fujiyoshi ${ }^{4}$, Yusuke Yanagi ${ }^{2}$, Koichiro Yoshimaru ${ }^{2}$, Makoto Hayashida ${ }^{2}$, Toshiharu Matsuura ${ }^{2}$, Reona Aijima ${ }^{1}$, Kenji Ihara ${ }^{5}$, Shouichi Ohga ${ }^{6}$, Songtao Shi ${ }^{7}$, Kazuaki Nonaka ${ }^{3}$ and Tomoaki Taguchi ${ }^{2^{*}}$

\begin{abstract}
Introduction: Liver transplantation is a gold standard treatment for intractable liver diseases. Because of the shortage of donor organs, alternative therapies have been required. Due to their potential to differentiate into a variety of mature cells, stem cells are considered feasible cell sources for liver regeneration. Stem cells from human exfoliated deciduous teeth (SHED) exhibit hepatogenic capability in vitro. In this study, we investigated their in vivo capabilities of homing and hepatocyte differentiation and therapeutic efficacy for liver disorders in carbon tetrachloride $\left(\mathrm{CCl}_{4}\right)$-induced liver fibrosis model mice.

Methods: We transplanted SHED into $\mathrm{CCl}_{4}$-induced liver fibrosis model mice through the spleen, and analyzed the in vivo homing and therapeutic effects by optical, biochemical, histological, immunological and molecular biological assays. We then sorted human leukocyte antigen-ABC (HLA-ABC)-positive cells from primary CCl4-damaged recipient livers, and analyzed their fusogenicity and hepatic characteristics by flow cytometric, genomic DNA, hepatocyte-specific gene assays. Furthermore, we examined the treatment effects of HLA-positive cells to a hepatic dysfunction by a secondary transplantation into $\mathrm{CCl}_{4}$-treated mice.

Results: Transplanted SHED homed to recipient livers, and expressed HLA-ABC, human hepatocyte specific antigen hepatocyte paraffin 1 and human albumin. SHED transplantation markedly recovered liver dysfunction and led to anti-fibrotic and anti-inflammatory effects in the recipient livers. SHED-derived HLA-ABC-positive cells that were sorted from the primary recipient liver tissues with $\mathrm{CCl}_{4}$ damage did not fuse with the host mouse liver cells. Sorted HLA-positive cells not only expressed human hepatocyte-specific genes including albumin, cytochrome P450 1A1, fumarylacetoacetase, tyrosine aminotransferase, uridine 5'-diphospho-glucuronosyltransferase, transferrin and transthyretin, but also secreted human albumin, urea and blood urea nitrogen. Furthermore, SHED-derived $\mathrm{HLA}$-ABC-positive cells were secondary transplanted into $\mathrm{CCl}_{4}$-treated mice. The donor cells homed into secondary recipient livers, and expressed hepatocyte paraffin 1 and human albumin, as well as HLA-ABC. The secondary transplantation recovered a liver dysfunction in secondary recipients.
\end{abstract}

Conclusions: This study indicates that transplanted SHED improve hepatic dysfunction and directly transform into hepatocytes without cell fusion in $\mathrm{CCl}_{4}$-treated mice, suggesting that SHED may provide a feasible cell source for liver regeneration.

\footnotetext{
* Correspondence: taguchi@pedsurg.med.kyushu-u.ac.jp

${ }^{\dagger}$ Equal contributors

${ }^{2}$ Department of Pediatric Surgery, Kyushu University Graduate School of

Medical Sciences, 3-1-1 Maidashi, Higashi-ku, Fukuoka 812-8582, Japan

Full list of author information is available at the end of the article
}

C Biomed Central

(C) 2015 Yamaza et al. Open Access This article is distributed under the terms of the Creative Commons Attribution 4.0 International License (http://creativecommons.org/licenses/by/4.0/), which permits unrestricted use, distribution, and reproduction in any medium, provided you give appropriate credit to the original author(s) and the source, provide a link to the Creative Commons license, and indicate if changes were made. The Creative Commons Public Domain Dedication waiver (http://creativecommons.org/publicdomain/zero/1.0/) applies to the data made available in this article, unless otherwise stated. 


\section{Introduction}

Hepatic fibrosis is a severe chronic condition that occurs as a result of various congenital and acquired hepatic disorders, including viral, drug-induced, cholestatic, metabolic, and autoimmune diseases. Cirrhosis, the most advanced stage of hepatic fibrosis, usually progresses to hepatocellular carcinoma, resulting in liver failure without the liver's usual self-regenerative capability. Unfortunately, current pharmaceutical and immunological treatments are unable to cure patients with hepatic fibrosis and/or cirrhosis. Liver transplantation is therefore the only treatment with clinical success. However, few patients benefit from organ grafting because of high medical expenses, the long-term wait for a donor liver, organ rejection, and complications [1]. Hepatocyte transplantation as an alternative is also associated with a limited cell supply and minimal engraft efficacy [2]. Another alternative therapy is therefore required urgently for hepatic fibrosis and/or cirrhosis. A concept of stem cell-based tissue engineering and regenerative medicine is expected to provide novel and promising therapeutics for refractory liver diseases [3].

Human mesenchymal stem cells (MSCs) exhibit selfrenewal and multipotency into a variety of mature cells, including hepatocytes [4]. Human MSCs have been identified in a variety of human tissues, including bone marrow [5], adipose tissue [6], umbilical cord blood [7], amniotic fluid stem cells [8], and dental pulp tissue [9]. Recent studies also evaluate immunomodulatory effects of MSCs [10]. MSCs are therefore considered a feasible cell source for tissue engineering and regenerative medicine [11]. Some clinical phase I, I/II, and II trials have demonstrated that human MSC transplantation recovers hepatic function in liver cirrhosis patients [12-14], indicating that human MSCs might be a promising candidate for treatments of liver dysfunction.

Stem cells from human exfoliated deciduous teeth (SHED) are a major focus area in tissue engineering and regenerative medicine. SHED are discovered in remnant dental pulp tissues of human exfoliated deciduous teeth, and share MSC characteristics, including fibroblastic features, clonogenicity, cell surface antigen expression, cell proliferative capacity, and multidifferentiation potency [15]. SHED also modulate immune responses of interleu kin-17-producing helper $\mathrm{T}$ (Th17) cells, regulatory $\mathrm{T}$ cells (Tregs), and dendritic cells [16, 17]. Recent studies have evaluated the latent potential of SHED in tissue engineering for bone regeneration $[18,19]$ and cell-based therapy for a variety of refractory systemic diseases, including systemic lupus erythematous, spinal cord injury, Parkinson's disease, and diabetes [16, 20-22]. Furthermore, cryopreservation of dental pulp tissues from human deciduous teeth has succeeded [23].

Accumulating evidence has demonstrated that a variety of human MSCs, including bone marrow-derived, adipose tissue-derived, umbilical cord blood-derived, and Wharton's jelly-derived MSCs, are capable of differentiating into hepatocyte-like cells in vivo in animal models of hepatic failure [24-26]. Advanced tissue engineering techniques accelerate a transdifferentiation ability of human MSCs into hepatocytes [27, 28]. In comparison with other human tissues, exfoliated deciduous teeth offer significant advantages of less ethical controversies and readily accessible source, easy and minimally invasive collection, and retain high stem cell potential such as cell proliferation, multipotency, and immunomodulatory functions [14-16], even after cryopreservation [23]. Recently, many investigators have investigated a SHED bank for allogenic cell therapy, as well as autologous cell therapy [23, 29, 30]. Exfoliated deciduous teeth might therefore be a feasible cell source for MSC-based therapy for both pediatric and adult patients with liver dysfunction.

Although SHED are known to be capable of differentiating into hepatocyte-like cells in vitro [31], they have not been evaluated for their in vivo hepatogenic capacity or therapeutic efficacy in liver disorders. In this study, we reveal that SHED transplantation recovers the liver dysfunction of carbon tetrachloride $\left(\mathrm{CCl}_{4}\right)$-treated mice. The engrafted SHED convert directly into human hepatocyte-like cells without fusion in fibrous livers of $\mathrm{CCl}_{4}$-treated mice. Furthermore, these in vivo SHEDconverted hepatocyte-like cells participate in the hepatic recovery via both direct (tissue replacement) and indirect (anti-fibrotic and anti-inflammatory effects) integration in $\mathrm{CCl}_{4}$-injured mouse livers.

\section{Methods}

Ethics statement and human subjects

Human samples were collected as discarded biological/ clinical samples from healthy pediatric donors (5-7 years old) in the Department of Pediatric Dentistry of Kyushu University Hospital, Fukuoka, Japan. Procedures using human samples were conducted in accordance with Declaration of Helsinki, and were approved by Kyushu University Institutional Review Board for Human Genome/Gene Research (Protocol Number: 393-01). Written informed consent was obtained from each parent on behalf of the child donors. All animal experiments were approved by Institutional Animal Care and Use Committee of Kyushu University (Protocol Number: A21-044-1).

\section{Isolation and culture of SHED}

Isolation and culture of SHED were performed according to our previous reports [16, 23]. The detailed method is described in Additional file 1. To confirm whether our isolated cells were MSCs, the obtained passage 3 (P3) cells were assessed by a flow cytometric analysis as described 
previously [16]. The P3 cells were also cultured under osteogenic, chondrogenic, and adipogenic conditions as described previously [23]. The P3 cells were positive for CD146, CD73, CD105, and CD90, but negative for hematopoietic markers (CD34, CD45, CD14, and CD11b) (Figure S1A in Additional file 2). The P3 cells also exhibited multipotency into three types of classical mesenchymal lineage cells (Figure S1B-G in Additional file 2). These phenotypes indicated that our isolated SHED fulfilled minimal and standard criteria for MSCs [32]. The P3 cells were therefore used for further experiments in this study.

\section{Chronic liver fibrosis model in mice}

A mixture of $\mathrm{CCl}_{4}(0.5 \mathrm{ml} / \mathrm{kg}$ body weight; Wako Pure Chemicals, Osaka, Japan) and olive oil (1:4 volume/volume; Wako Pure Chemicals) was injected intraperitoneally into C57BL/6J mice (male, 8 weeks old; Kyudo, Tosu, Japan) twice a week during this experimental period (see Fig. 1a).
Age-matched and sex-matched mice injected with olive oil (Wako Pure Chemicals) were used as controls for primary $(n=5)$ and secondary $(n=5)$ transplantation.

\section{Primary transplantation of SHED}

One million SHED (P3) suspended in $100 \mu$ l phosphatebuffered saline (PBS) were intrasplenically transplanted into mice treated with $\mathrm{CCl}_{4}$ for 4 weeks $(n=5)$ (Fig. 1a). As a control, $100 \mu \mathrm{l}$ PBS were infused intrasplenically into mice treated with $\mathrm{CCl}_{4}$ for 4 weeks $(n=5)$. The mice continuously received $\mathrm{CCl}_{4}$ twice a week for an additional 4-week treatment after the transplantation. All of the animals were sacrificed to harvest the livers and peripheral blood.

\section{Colorimetric analysis and enzyme-linked immunosorbent assay of mouse serum and liver samples}

Serum alkaline phosphatase (ALP), alanine aminotransferase (ALT), aspartate aminotransferase (AST), and total

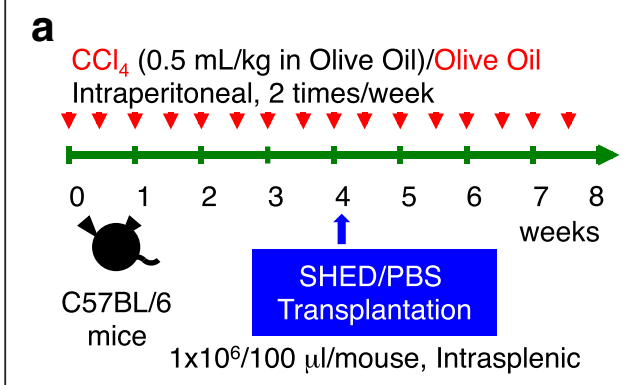

d

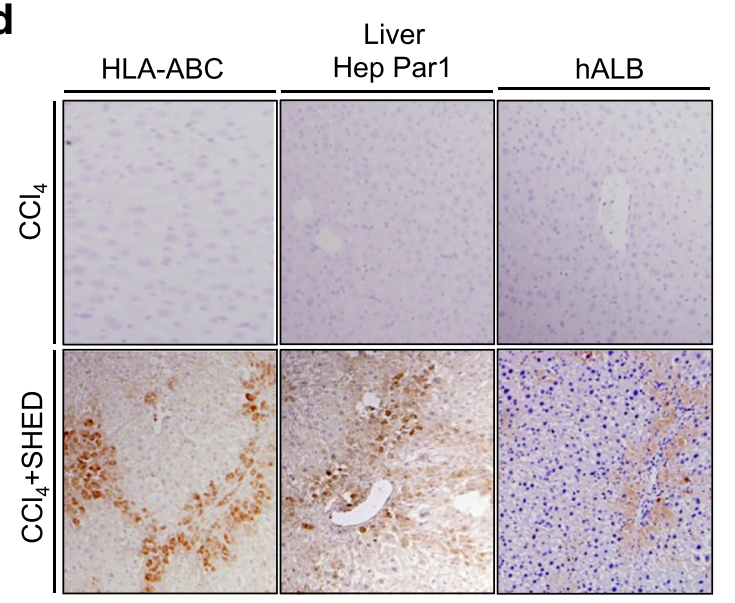

b

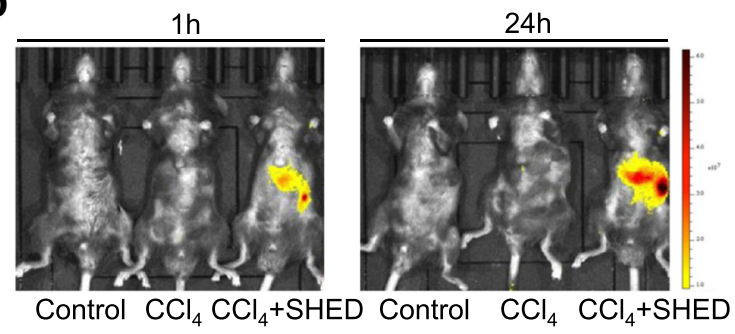

e Liver f Liver Ab-positive Area Ab-positive Area (\%/Total Area) (\%/Fibrous Area) (1)

Fig. 1 SHED differentiate into human hepatocyte-like cells in recipient livers of $\mathrm{CCl}_{4}$-treated mice. a Schema of $\mathrm{CCl}_{4}$ treatment and SHED transplantation in mice. C57BL/6 mice intraperitoneally received $\mathrm{CCl}_{4}(0.5 \mathrm{ml} / \mathrm{kg})$ or olive oil only twice a week (red arrows). Four weeks after the treatment, SHED $\left(1 \times 10^{6}\right)$ were transplanted into the $\mathrm{CCl}_{4}$-treated mice through the spleen. Phosphate-buffered saline (PBS) was infused as the control for the transplantation. $\mathbf{b}$ In vivo monitoring of transplanted DiR-labeled SHED in $\mathrm{CCl}_{4}$-treated mice 1 hour (1h) or 24 hours (24h) after the infusion. Dorsal position. c Enzyme-linked immunosorbent assay of human albumin (hALB) in the recipient serum. $\mathbf{d}-\mathbf{f}$ Distribution of transplanted SHED in recipient livers. Immunohistochemistry with anti-human HLA-ABC, anti-hepatocyte paraffin 1 (Hep Par1), or anti-hALB antibody. Representative images. d Counterstaining with hematoxylin. The human HLA-ABC, hepatocyte paraffin 1, or hALB antibody positive area. Immunopositive area shown as the ratio to $\mathbf{e}$ the total area or $\mathbf{f}$ the fibrous area. $\mathbf{c}, \mathbf{e}, \mathbf{f} n=5$ for all groups. ${ }^{*} P<0.05$ and ${ }^{* * *} P<0.005$. $n s$ no significance. Graph bars show mean \pm SD. Control, olive oil-injected group; $\mathrm{CCl}_{4}, \mathrm{CCl}_{4}$-treated group; $\mathrm{CCl}_{4}+\mathrm{SHED}$, SHED-transplanted CCl -treated group. $\mathrm{Ab}$ antibody, $\mathrm{CCl}_{4}$ carbon tetrachloride, HLA human leukocyte antigen, SHED stem cells from human exfoliated deciduous teeth 
bilirubin were measured with a Multiskan GO microplate spectrophotometer (Thermo Scientific, Waltham, MA, USA) using commercially available kits according to the manufacturer's protocol: ALP, LabAssay ALP Kit (Wako Pure Chemicals); ALT and AST, Transaminase CII-Test Kit (Wako Pure Chemicals); and total bilirubin, Bilirubin QuantiChrom Assay Kit (BioAssay Systems, Hayward, CA, USA). Liver hydroxyproline contents were measured with a Multiskan GO microplate spectrophotometer (Thermo Scientific) using a Hydroxyproline Assay Kit (Biovision, Milpitas, CA, USA). Serum mouse interleukin (IL)-6, IL-10, IL-17, transforming growth factor $\beta 1$ (TGF- $\beta 1$ ), and tumor necrosis factor alpha (TNF $\alpha$ ) were also measured using Quantikine ELISA kits (R\&D Systems, Minneapolis, MN, USA).

\section{Histological and immunohistochemical analyses of mouse liver tissues}

Tissue preparation, Masson's trichrome staining, and immunohistochemical staining were performed as described in Additional file 1. The sections were observed under an Axio Imager M2 (Zeiss, Oberkochen, Germany) for morphometric assays, and five representative images from each mouse were selected randomly and were used to measure a percentage of fibrous tissue area or primary antibody-positive area using Image software $(\mathrm{NIH}$, Bethesda, MD, USA). Trichrome stained sections were analyzed to score the amount of liver disease using Ishak scoring [33].

\section{Double immunofluorescence}

Double immunofluorescent staining was performed as described in Additional file 1. The sections were observed under an Axio Imager M2 (Zeiss).

\section{Quantitative real-time RT-PCR assay}

Total RNAs were extracted and treated as described in Additional file 1. Real-time RT-PCR was subsequently performed using a TaqMan Gene Expression Master Mix (Applied Biosystems, Foster City, CA, USA) and target TaqMan probes (Applied Biosystems) (Table S1 in Additional file 3) with a Light Cycler 96 (Roche, Indianapolis, IN, USA). $18 \mathrm{~S}$ ribosomal RNA was used for normalization.

\section{Sorting of HLA-ABC-positive or HLA-negative cells from} liver tissues of $\mathrm{CCl}_{4}$-treated mice transplanted with SHED Livers of primary recipients $(n=5)$ were perfused with collagenase type $\mathrm{H}(0.1 \mathrm{mg} / \mathrm{ml}$; Worthington Biochemicals, Lakewood, NJ, USA) in PBS and gently dispersed. Single suspended cells were stained with phycoerythrin (PE)-conjugated anti-human leukocyte antigen (HLA)$\mathrm{ABC}$ (eBioscience, San Diego, CA, USA) and magnetic bead-conjugated anti-PE antibodies (Miltenyi Biotec,
Bergisch Gladbach, Germany). They were magnetically sorted using a MidiMACS separator (Miltenyi Biotec) equipped with a LD column (Miltenyi Biotec), and the positive and negative fractions were collected separately.

\section{Cell fusion assay in HLA-positive cells}

Magnetically sorted HLA-ABC-positive and HLA-negative fractions were stained with $\mathrm{PE}$-conjugated anti-human major histocompatibility complex (MHC) class I HLA$\mathrm{ABC}$ (eBioscience) and allophycocyanin (APC)-conjugated anti-mouse major MHC class I H-2Kb (eBioscience) antibody. The cells were measured with a FACS Verse flow cytometer (BD Biosciences, San Jose, CA, USA), and were analyzed by BD FACS Suite software (BD Biosciences).

\section{Human-specific genome assay in HLA-positive cells}

Genomic DNA was extracted from HLA-ABC-positive and HLA-negative fractions using a DNeasy Blood and Tissue Kit (Qiagen, Venlo, the Netherlands), and was amplified with a T-100 thermal cycler (Bio-Rad, Hercules, CA, USA) using Quick Taq HS DyeMix (TOYOBO, Osaka, Japan) and specific primer pairs by PCR assay. The specific primer pairs are presented in Table S2 in Additional file 3.

\section{Characterization of HLA-positive cells as human hepatocytes}

Sorted HLA-ABC-positive cells were cultured with Iscove's modified Dulbecco's medium (Invitrogen, Waltham, MA) supplemented with epidermal growth factor (EGF) (20 ng/ ml; PeproTech, Rocky Hill, NJ, USA), fibroblast growth factor 2 (FGF2) $(10 \mathrm{ng} / \mathrm{ml}$; PeproTech), and hepatocyte growth factor (HGF) $(20 \mathrm{ng} / \mathrm{ml}$; PeproTech). Some cultures were stained with toluidine blue.

Expression of human hepatocyte-specific genes in HLA-positive cells was analyzed by RT-PCR with a T100 thermal cycler (Bio-Rad) as described previously $[16,23]$. The specific primer pairs are presented in Table S2 in Additional file 3. HepG2 cells (Riken, Tsukuba, Japan) were used as positive control. Human albumin and urea in the culture supernatants of HLA-positive cells were measured with a Multiskan GO microplate spectrophotometer (Thermo Scientific) using a Human Albumin ELISA Quantitation Set (AssayPro, St Charles, MO, USA) and a QuantiChrom Urea Assay Kit (Bioassay Systems), respectively.

Secondary transplantation of HLA-ABC-positive or HLAnegative cells sorted from liver tissues of $\mathrm{CCl}_{4}$-treated mice with primary transplantation of SHED

To understand whether SHED-derived in vivo-converted hepatocyte-like cells express hepatic function in vivo, we performed a secondary transplantation of the SHED- 
derived in vivo-converted hepatocyte-like cells into $\mathrm{CCl}_{4}$-damaged mice. The mice ( $n=5$ each) were treated with $\mathrm{CCl}_{4}$ for 4 weeks, and were then transplanted with 1 million HLA-positive or HLA-negative cells via the spleen and continuously received $\mathrm{CCl}_{4}$ twice a week for an additional 4-week treatment after the transplantation (shown in Fig. 6a). We also used $\mathrm{CCl}_{4}$-treated mice and nontreated mice without the cell transplant ( $n=5$ each). Finally, the peripheral blood serum and liver samples were harvested, and used for further experiments.

\section{In vivo monitoring of transplanted cells}

Cells were labeled with near-infrared (NIR) lipophilic carbocyanine membrane dye, 1,1-dioctadecyl-3,3,3,3tetramethylindotricarbocyanine iodide (DiR). The cells $\left(1 \times 10^{7}\right.$ in $10 \mathrm{ml}$ PBS $)$ were incubated with XenoLight DiR NIR Fluorescent Dye $(10 \mu \mathrm{g} / \mathrm{ml}$; Perkin Elmer, Waltham, MA, USA) for 30 minutes at $37^{\circ} \mathrm{C}$, and were then washed twice with PBS. In vivo optical imaging was performed to detect the transplanted cells. The labeled cells $\left(1 \times 10^{6}\right.$ in $100 \mu \mathrm{l}$ PBS) were infused intrasplenically into $\mathrm{CCl}_{4}$-pretreated mice $(n=5)$. As a control for cell transplantation, nonlabeled SHED $\left(1 \times 10^{6}\right.$ in $100 \mu \mathrm{l} \mathrm{PBS)}$ were infused into $\mathrm{CCl}_{4}$-pretreated mice via the spleen $(n=5)$. Ventral images were captured from each animal group after 1 or 24 hours under an optical in vivo imaging system IVIS Lumina III (Perkin Elmer), and were analyzed using living image software (Perkin Elmer).

\section{Statistical analysis}

Statistical results are expressed as mean \pm standard deviation (SD). Multiple group comparison was analyzed by one-way repeated-measures analysis of variance followed by the Tukey post hoc test using PRISM 6software (GraphPad, Software, La Jolla, CA, USA). $P<0.05$ was considered significant.

\section{Results}

Transplanted donor SHED are capable of homing and differentiating into human hepatocyte-like cells in recipient livers of $\mathrm{CCl}_{4}$-injured mice

Mouse livers showed fibrosis after 4 weeks of treatment with $\mathrm{CCl}_{4}$ (data not shown). To address a therapeutic potential of SHED for liver disorders, SHED $\left(1 \times 10^{6}\right.$ per mouse) were intrasplenically injected into mice that had been treated with $\mathrm{CCl}_{4}$ for 4 weeks (Fig. 1a). We first investigated whether transplanted SHED were capable of engrafting in the $\mathrm{CCl}_{4}$-treated mouse liver parenchyma. DiR-labeled SHED were infused into a spleen of $\mathrm{CCl}_{4}$ treated mice. In vivo imaging demonstrated that the intensity of DiR was detected on the liver, as well as the spleen, 1 hour after transplantation (Fig. 1b). The signals were enhanced in both the liver and spleen 24 hours after transplantation (Fig. 1b). Non-CCl ${ }_{4}$-treated mice and non-SHED-infused $\mathrm{CCl}_{4}$-treated mice expressed no signal at 1 and 24 hours after transplantation (Fig. 1b). By the carboxyfluorescein diacetate succinimidyl ester (CFSE)-labeled cell trace technique, CFSE-labeled SHED were detected in $\mathrm{CCl}_{4}$-damaged mouse liver 1 day after the transplantation (Figure S2 in Additional file 2). Our immunohistochemical analysis also detected positive immunoreactions to anti-HLA-ABC antibody in spleens of $\mathrm{CCl}_{4}$-damaged mice, but negative immunoreaction to anti-HLA-ABC antibody in spleens of $\mathrm{CCl}_{4}$-damaged mice (Figure S3B, $C$ in Additional file 2). In addition, no immunoreaction to anti-HLA-ABC and anti-hepatocyte paraffin 1 antibodies was detected in the kidneys and lungs of $\mathrm{CCl}_{4}$-damaged mice (Figure S3B, C in Additional file 2). These findings suggested that DiR-labeled SHED were recruited to CCl4-damaged liver from the transplanted site, the spleen.

To confirm in vivo homing of transplanted SHED, peripheral blood serum and liver tissues were harvested from SHED-transplanted $\mathrm{CCl}_{4}$-treated mice, nontransplanted $\mathrm{CCl}_{4}$-treated mice, and non- $\mathrm{CCl}_{4}$-treated mice in week 8. Enzyme-linked immunosorbent assay (ELISA) detected human albumin in the serum of SHEDtransplanted $\mathrm{CCl}_{4}$-treated mice, but not in both nontransplanted $\mathrm{CCl}_{4}$-treated mice and non- $\mathrm{CCl}_{4}$-treated mice (Fig. 1c). An immunohistochemical assay demonstrated that HLA-ABC-positive cells with a cuboidal shape were found in the interlobular and portal areas (Fig. 1d), which corresponded to the fibrotic region in $\mathrm{CCl}_{4}$-injured liver tissues (Fig. 2b). The HLA-ABC-positive cells occupied $16.27 \pm 10.17 \%$ of the recipient liver tissues (Fig. 1e). Furthermore, to verify whether the transplanted donor cells differentiated into human hepatocytes in recipient livers, immunohistochemical assay was performed using human hepatocyte-specific hepatocyte paraffin 1 and human albumin-specific antibodies. The hepatocyte paraffin 1-positive and human albumin-positive cells were distributed in interlobular and portal areas of the recipient livers similar to the HLA-ABC-positive cells (Fig. 1d), and were expressed in $11.39 \pm 4.58 \%$ and $10.73 \pm 6.18 \%$ of the recipient liver tissues, respectively (Fig. 1e). The hepatocyte paraffin 1-positive and human albumin-positive areas tended to be less than the HLA$\mathrm{ABC}$-positive area, but not significant (Fig. 1e). No immunoreactivity against HLA-ABC, hepatocyte paraffin 1, or human albumin was found in the liver tissue of nontransplanted $\mathrm{CCl}_{4}$-induced mice (Fig. 1d) or in control mice (data not shown). No immunoreactivity against HLA-ABC, hepatocyte paraffin 1, or human albumin is found for liver sections treated with nonimmune IgG instead of the primary antibodies (Figure S4 in Additional file 2). Positive immunoreaction to antiHLA-ABC, anti-hepatocyte paraffin 1, and anti-human 


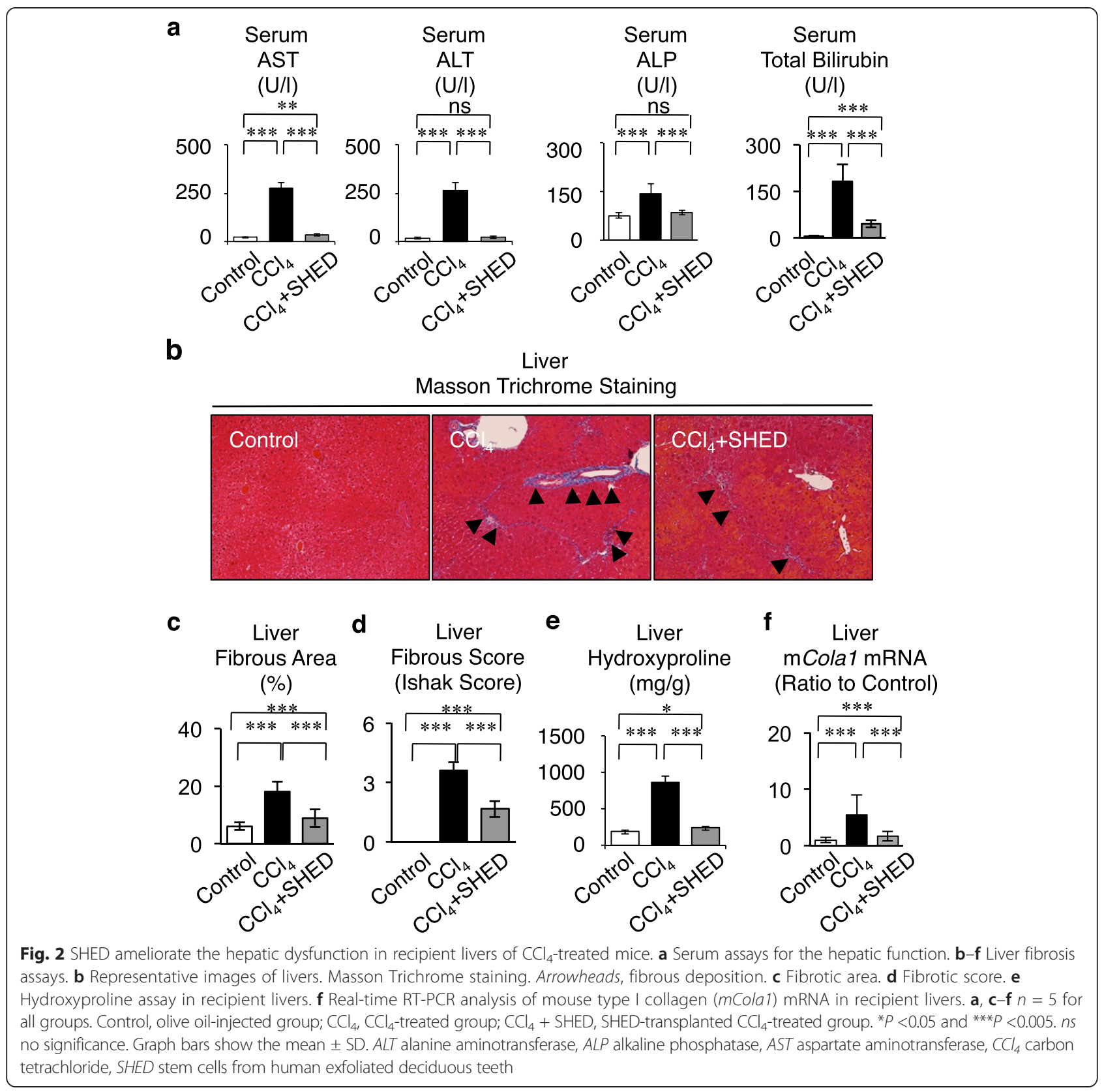

albumin antibodies was detected in almost of parenchymal cells of human liver tissues (Figure S5 in Additional file 2), but human liver tissues expressed negative immunoreaction to nonimmune mouse IgG (Figure S5 in Additional file 2). These results indicated that donor SHED showed an in vivo capacity of engrafting and differentiating into human hepatocyte-like cells in the recipient livers of $\mathrm{CCl}_{4}$-injured mice.

\section{SHED transplantation decreased $\mathrm{CCl}_{4}$-induced chronic fibrosis in mouse livers}

To address whether SHED have therapeutic potential for liver disorders, SHED-transplanted $\mathrm{CCl}_{4}$-treated mice, as well as nontransplanted (PBS-injected) $\mathrm{CCl}_{4}$ treated mice, received continuous $\mathrm{CCl}_{4}$ injections for an additional 4 weeks (Fig. 1a). In week 8 , the nontransplanted mice showed severe fibrous liver dysfunction (Fig. 2). A biochemical serum assay revealed that SHED transplantation markedly recovered the damaged liver functions (Fig. 2a). Masson trichrome staining showed that SHED transplantation reduced $\mathrm{CCl}_{4}$-enhanced fibrous deposition in the liver (Fig. 2b, c). The fibrous tissue area occupied $5.98 \pm 1.35 \%, 18.16 \pm 3.36 \%$, and $8.89 \pm 3.07 \%$ of the recipient liver tissues in control mice, nontransplanted $\mathrm{CCl}_{4}$-treated mice, and SHEDtransplanted $\mathrm{CCl}_{4}$-treated mice, respectively (Fig. 2c). 
The degree of hepatic fibrosis by Ishak score [31] was $0 \pm 0,3.60 \pm 0.43$, and $1.67 \pm 0.41$ of the recipient liver tissues in control mice, nontransplanted $\mathrm{CCl}_{4}$-treated mice, and SHED-transplanted $\mathrm{CCl}_{4}$-treated mice, respectively (Fig. 2d). Colorimetric and real-time PCR assays revealed that SHED transplantation significantly reduced the hydroxyproline content and collagen production in the $\mathrm{CCl}_{4}$-damaged liver tissues (Fig. 2e, f). Interestingly, HLA-ABC, hepatocyte paraffin 1, or human albumin-positive cells captured a similar area to the fibrous deposit region in the liver of nontransplanted $\mathrm{CCl}_{4}$-treated mice (Fig. $1 \mathrm{~d}-\mathrm{f}$ ). To confirm the in vivo hepatogenic differentiation capacity and therapeutic efficacy of SHED in recipient $\mathrm{CCl}_{4}$-injured livers, we infused pediatric human gingival fibroblasts as a control for SHED transplantation in $\mathrm{CCl}_{4}$-treated mice (Figure S6A in Additional file 2). Immunohistochemical assay showed that no HLA-ABC, hepatocyte paraffin 1, or human albumin-positive human cells were detected in the recipient $\mathrm{CCl}_{4}$-damaged liver tissues (Figure S6B in Additional file 2). Biochemical assays demonstrated that human gingival fibroblast infusion did not recover the impaired hepatic function in $\mathrm{CCl}_{4}$-injected mice (Figure S6C in Additional file 2). Taken together, these findings indicated that SHED transplantation suppressed $\mathrm{CCl}_{4}$-enhanced fibrous deposition in the liver of $\mathrm{CCl}_{4}$ treated mice, and suggested that SHED directly/spontaneously transdifferentiated into human hepatocytes in $\mathrm{CCl}_{4}$-damaged livers.

Activation of hepatic stellate cells is a crucial event required to initiate and promote hepatic fibrosis, followed by producing and remodeling of type I collagen by matrix metalloproteinases (MMPs) and tissue inhibitors of metalloproteinase (TIMPs) [34]. We therefore examined the kinetics of activated hepatic stellate cells after SHED transplantation in recipient livers 8 weeks after the first $\mathrm{CCl}_{4}$ injection. Immunohistochemical analysis indicated that SHED transplantation decreased the area of alpha smooth muscle actin ( $\alpha \mathrm{SMA}$ )-positive cells, which indicated activated hepatic stellate cells, in the $\mathrm{CCl}_{4}$-injured liver tissues (Fig. 3a, b). A real-time PCR assay also demonstrated that SHED transplantation significantly reduced the expression of $\alpha$ SMA mRNA (Fig. 3c) and markedly suppressed $\mathrm{CCl}_{4}$-induced MMP2, MMP9, TIMP1, and TIMP2 mRNA expression (Fig. 3d) in the injured livers.

Kupffer cells and $\mathrm{T}$ lymphocytes and the fibrotic and inflammatory cytokines, such as TGF- $\beta$, TNF $\alpha$, IL- 6 , and IL-17, produced by them are also involved in the progression of hepatic fibrosis and activation of hepatic stellate cells $[34,35]$. By immunohistochemical assays, $\mathrm{CCl}_{4}$ treatment markedly induced infiltration of F4/80-positive and CD3-positive cells in the liver, which indicate Kupffer cells and/or macrophages and $\mathrm{T}$ lymphocytes, respectively, compared with non- $\mathrm{CCl}_{4}$-treated livers (Fig. 4a-c). SHED transplantation suppressed the altered distribution of F4/80-positive and CD3-positive cells in the $\mathrm{CCl}_{4}$-treated livers (Fig. 4a-d). Further histochemical analysis demonstrated that SHED transplantation did not induce any heavy infiltration of lymphocyte-like cells, and did not cause any severe change of structural components in other tissues such as the kidneys, lungs, and spleens of $\mathrm{CCl}_{4}$-treated mice with SHED (Figure S3A in Additional file 2). Real-time PCR and ELISA studies demonstrated that SHED transplantation reduced the expression of TGF- $\beta 1$, TNF $\alpha$, and IL- 6 mRNAs in the $\mathrm{CCl}_{4}$-induced fibrous livers (Fig. 3e), and suppressed the elevation of IL- 6 , TGF- $\beta$, and TNF $\alpha$ in the serum of $\mathrm{CCl}_{4}$-treated mice (Fig. 4e). SHED transplantation reduced the proinflammatory IL-17 expression and recovered the decreased anti-inflammatory IL-10 expression in the $\mathrm{CCl}_{4}$-treated livers (Fig. 4e). Taken together, these findings indicated that transplanted SHED might exhibit anti-fibrotic and anti-inflammatory effects against liver fibrosis by suppressing the activation of hepatic stellate cells, Kupffer cells/macrophages, and T cells.

\section{Donor SHED are capable of differentiating into human hepatocyte-like cells without fusion in $\mathrm{CCl}_{4}$-injured mouse livers}

Transplanted bone marrow cells fuse with host hepatocytes in damaged livers [36, 37], but bone marrow MSCs differentiate into hepatocytes without cell fusion in recipients [24]. Using dual immunofluorescent staining using human specific antibodies to hepatocyte paraffin 1 and albumin, we demonstrated that double positive cells to hepatocyte paraffin 1 and human albumin were found in liver tissues of $\mathrm{CCl}_{4}$-injured mice with SHED transplantation (Fig. 5a). However, it was unclear whether the double positive cells were fused with host cells or not; a possibility of cell fusion between donor SHED and recipient hepatocytes remained. To evaluate whether the in vivo converted SHED-derived human hepatocyte-like cells were fused with host hepatocytes, we isolated human cells from recipient livers of SHED-transplanted $\mathrm{CCl}_{4}$-treated mice (Figure S7 in Additional file 2). Panliver cells were isolated from the recipient livers with the collagenase digestion method, and stained with antiHLA-ABC antibody. The HLA-ABC-positive cells were magnetically sorted to collect separately from HLAABC-negative cells. Flow cytometric analysis confirmed that the HLA-ABC-positive fraction was $95.5 \pm 4.43 \%$ positive to HLA-ABC, but negative to mouse $\mathrm{H}-2 \mathrm{~Kb}$ (Fig. 5b). Double positive cells were also not detected (Fig. 5b). On the other hand, the HLA-ABC-negative fraction was $96.3 \pm 5.68 \%$ positive to $\mathrm{H}-2 \mathrm{~Kb}$, but $0 \%$ to HLA-ABC (data not shown). The HLA-ABC-positive cells maintained under EGF, FGF2, and HGF 


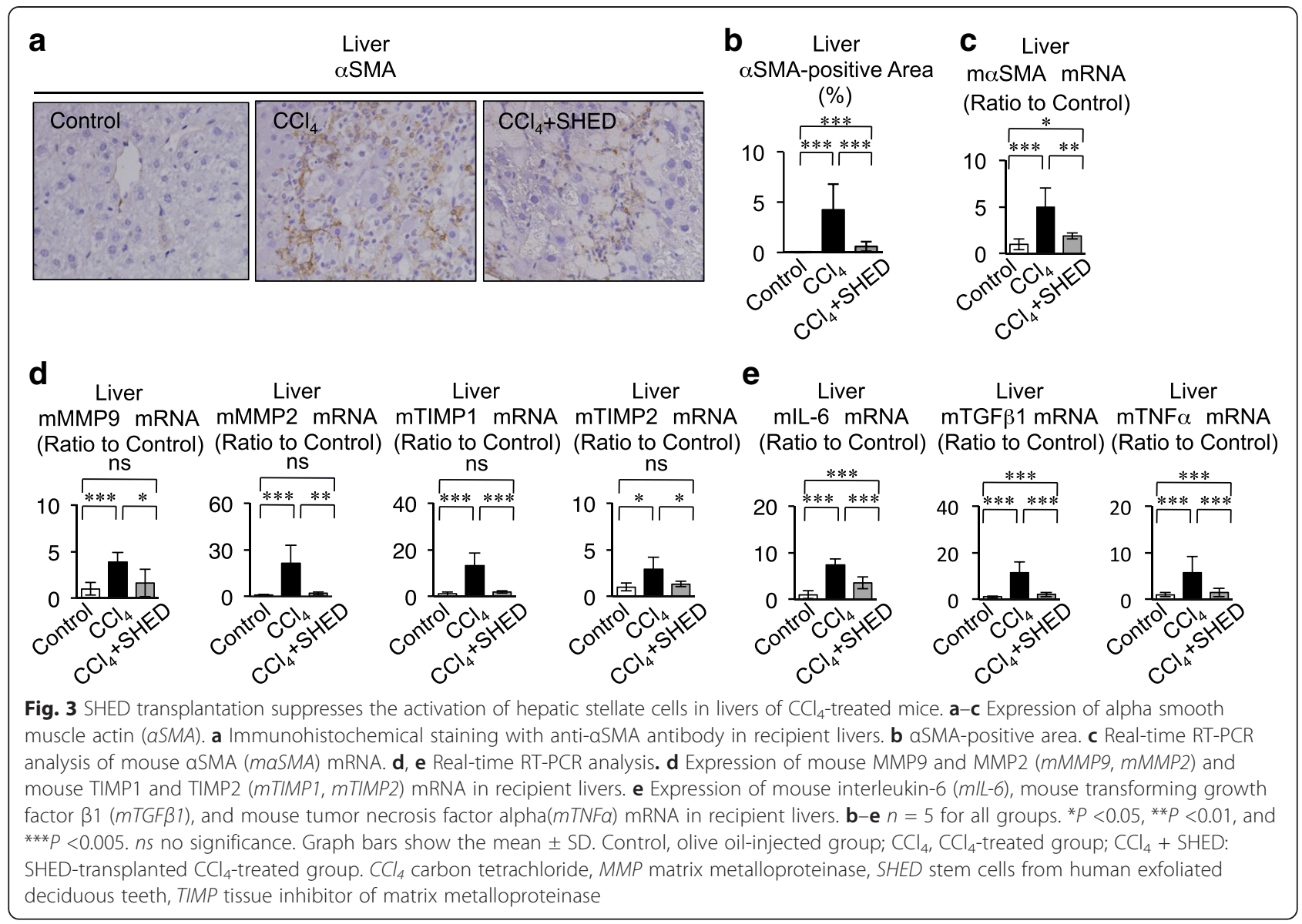

stimulation for 3 days showed a cuboidal shape on the dishes by toluidine blue staining (Fig, 5c). A genomic DNA assay demonstrated that a human specific gene, Alu, was detected only in HLA-ABC-positive cells, but not in HLA-ABC-negative cells (Fig. 5d). On the other hand, a mouse specific gene, $m p f 1$, was not detected in HLA-ABC-positive cells, but was found in HLA-ABCnegative cells (Fig. 5d). RT-PCR analysis also demonstrated that human albumin gene was detected only in HLA-ABC-positive cells, but not in HLA-ABC-negative cells, while mouse albumin gene was expressed in HLA-ABC-negative cells, but not in HLA-ABC-positive cells (Fig. 5e). These data indicate that transplanted SHED were directly transdifferentiated into human hepatocytes without fusion with recipient mouse hepatocytes.

Further RT-PCR assay demonstrated that the purified HLA-ABC-positive cells expressed human hepatocytespecific genes, albumin, cytochrome P450 1A1, cytochrome P450 3A7, fumarylacetoacetase, tyrosine aminotransferase, uridine 5 '-diphospho (UDP)-glucuronosyltransferase, transferrin, and transthyretin (Fig. 5f). However, the expression levels of human hepatocyte-specific genes in the purified HLA-ABC-positive cells were lower when compared with human hepatocyte cell line HepG2 (Fig. 5f). By ELISA and colorimetric assay, human albu$\mathrm{min}$, urea, and blood urea nitrogen were detected at $4.8 \pm$ $0.085 \mathrm{ng} / \mathrm{ml}, 0.47 \pm 0.01 \mathrm{mg} / \mathrm{dl}$, and $0.22 \pm 0.005 \mathrm{mg} / \mathrm{dl}$, respectively, in the culture supernatant of HLA-positive cells cultured with EGF, FGF2, and HGF stimulation for 3 days. Taken together, these findings indicate that SHED might show a potential for transdifferentiating into functional human hepatocytes, at least partially, without fusing with host mouse hepatocytes in fibrotic livers of $\mathrm{CCl}_{4^{-}}$ treated mice.

\section{Secondary transplantation of SHED-derived human hepatocyte-like cells purified from primary $\mathrm{CCl}_{4}$-injured recipient livers recovered hepatic dysfunction of $\mathrm{CCl}_{4}$-treated mice}

Next we examined the homing capability of SHEDderived in vivo-converted hepatocyte-like cells. Mice that had been treated with $\mathrm{CCl}_{4}$ for 4 weeks underwent secondary transplantation of purified HLA-ABCpositive cells $\left(1 \times 10^{6}\right)$, as well as HLA-ABC-negative cells $\left(1 \times 10^{6}\right)$, into the spleen (Fig. 6a). In vivo imaging analysis showed that strong intensity of DiR-labeled HLA-ABC-positive and DiR-labeled HLA-ABC-negative 


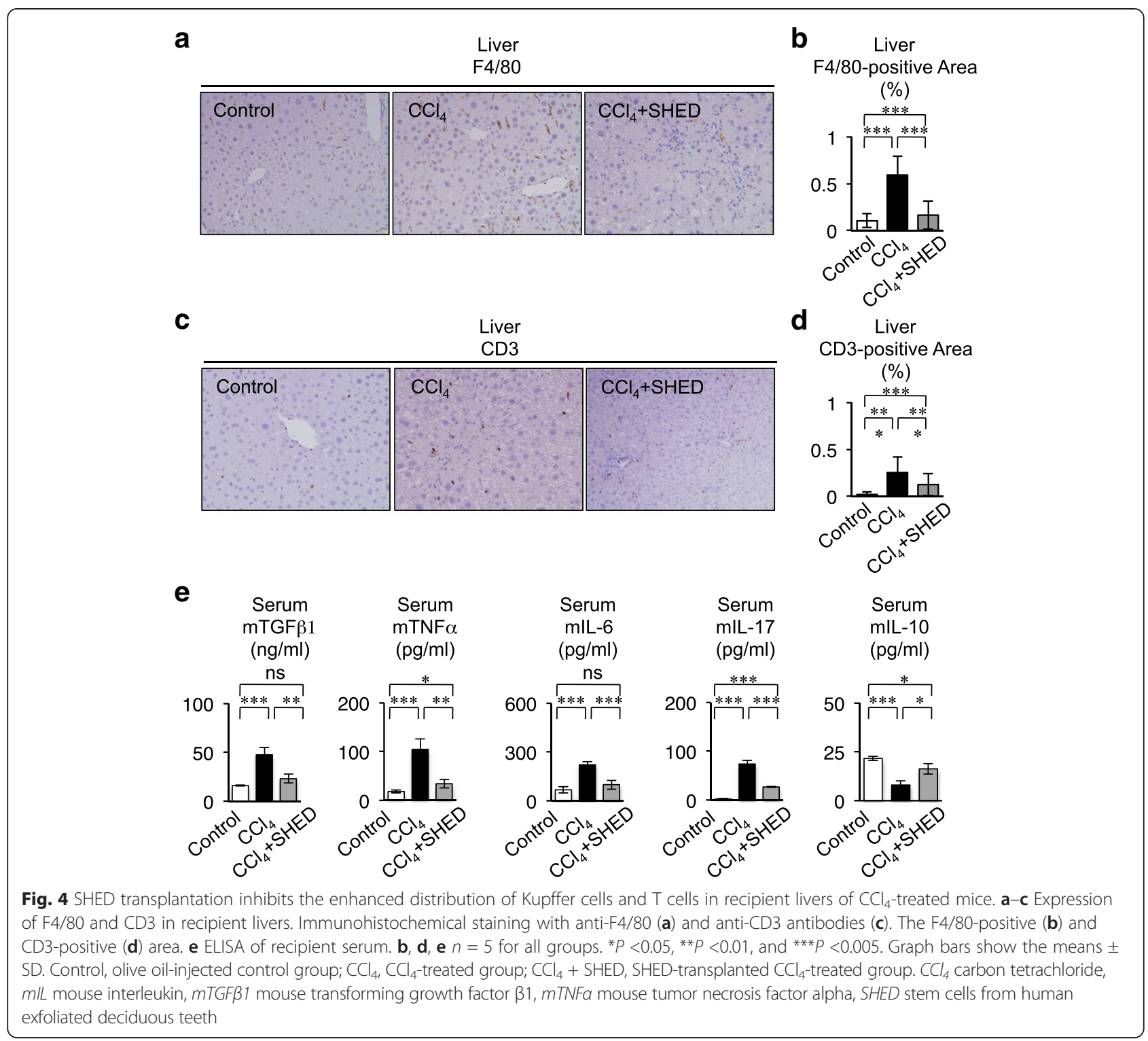

cells was observed in the livers of $\mathrm{CCl}_{4}$-treated mice 24 hours post transplantation (Fig. 6b). Further immunohistochemical analysis and ELISA was performed in the liver tissues and peripheral blood serum of $\mathrm{CCl}_{4}$-treated mice that underwent secondary transplantation with HLAABC-positive and HLA-ABC-negative cells, as well as of nontransplanted $\mathrm{CCl}_{4}$-treated mice and nonCCl 4 -treated mice, in week 8 .

An immunohistochemical examination demonstrated that HLA-ABC-positive, hepatocyte paraffin 1-positive, and human albumin-positive cells were observed in the interlobular and portal regions corresponding to the fibular deposited area in liver tissues of $\mathrm{CCl}_{4}$-treated mice that underwent secondary transplant with HLA$\mathrm{ABC}$-positive cells 4 weeks after the primary transplant (Fig. 6c). The HLA-ABC-positive, hepatocyte paraffin 1-positive, and human albumin-positive cell areas were $23.22 \pm 6.81 \%, 19.31 \pm 5.06 \%$, and $17.80 \pm 4.71 \%$ in the secondary recipient livers (Fig. 6d). The immunohistochemically positive areas expressed a similar rate to the liver fibrous area of nontransplanted $\mathrm{CCl}_{4}$-injured mice (Figure S8 in Additional file 2). No immunoreactivity against $\mathrm{HLA}-\mathrm{ABC}$, hepatocyte paraffin 1 , or human albumin was detected in the liver tissues of $\mathrm{CCl}_{4}$-induced mice that underwent secondary transplant with HLA-ABC-negative cells (Fig. 6c) or in nontransplanted $\mathrm{CCl}_{4}$-induced mice and non- $\mathrm{CCl}_{4}$-induced mice (data not shown). ELISA also showed that serum human albumin was detected in $\mathrm{CCl}_{4}$-treated mice that underwent secondary transplant with HLA-ABC-positive cells, but not in $\mathrm{CCl}_{4}$-treated mice that underwent secondary transplant with HLA-ABC-negative cells, 
a

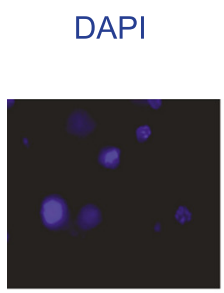

b

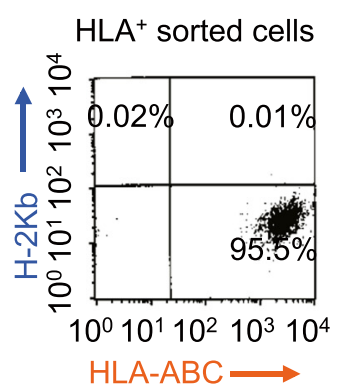

HepPar +DAPI

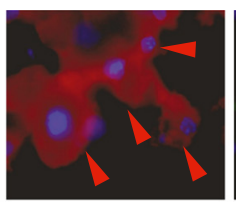

C $\mathrm{HLA}^{+}$sorted cells

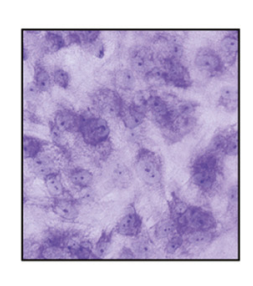

d

Alu

mpf1
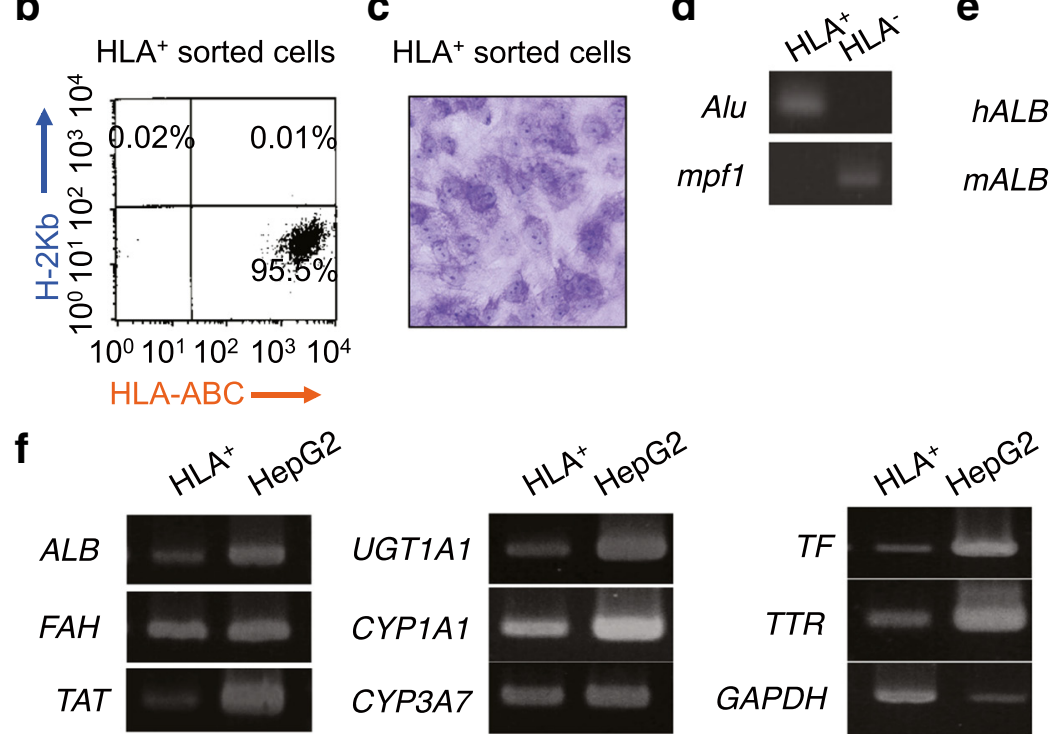

Fig. 5 SHED-derived HLA-ABC-positive cells purified from primary recipient livers of $\mathrm{CCl}_{4}$-treated mice express hepatocyte-specific genes without host-cell fusion. a Double-immunofluorescent staining patterns for HepPar and human albumin (hALB) in $C_{C C} \mathrm{I}_{4}$-injured liver tissues transplanted with SHED. b Flow cytometric analysis of magnetically sorted HLA-ABC-positive (HLA ${ }^{+}$) cells stained with PE-conjugated anti-human HLA-ABC and APC-conjugated anti-mouse H-K2 ${ }^{b}$ antibodies. c Morphology of sorted HLA ${ }^{+}$cells. Toluidine blue staining. $\mathbf{d}$ Genomic DNA assay. e RT-PCR analysis of hALB and mouse albumin (mALB) mRNAs. $\mathbf{f}$ RT-PCR analysis of human hepatocyte-specific genes. ALB albumin, Alu human-specific Alu gene, $\mathrm{CCl}_{4}$ carbon tetrachloride, CYP1A1 cytochrome P450 1A1, CYP3A7 cytochrome P450 3A7, DAPI 4',6-diamidino-2-phenylindole, FAH fumarylacetoacetate hydrolase, GAPDH human glyceraldehyde 3-phosphate dehydrogenase, HepG2 human hepatoma cell line, HepPar1 human hepatocyte specific HepParaffin 1 antigen, HLA human leukocyte antigen, HLA- HLA-ABC-negative cells, mpf1 mouse-specific Pf1 gene, SHED stem cells from human exfoliated deciduous teeth, TAT tyrosine aminotransferase, TF transferrin, TTR transthyretin, UGTIA1 uridine

5'-diphospho-glucuronosyltransferase 1A1

nontransplanted $\mathrm{CCl}_{4}$-treated mice, and non- $\mathrm{CCl}_{4}$-treated mice (Fig. 6e).

To evaluate a therapeutic efficacy of SHED-derived in vivo-converted hepatocyte-like cells, peripheral blood serum and liver tissues were harvested from the mice in week 8 . Serum assay demonstrated that the secondary transplantation of primary HLA-ABC-positive cells recovered hepatic markers of $\mathrm{CCl}_{4}$-treated mice (Fig. 7a; Figure S9 in Additional file 2). Masson trichrome staining and hydroxyproline content assay demonstrated that the secondary transplantation of primary HLA-ABC-positive cells reduced the production and deposition of fibrous matrix (Fig. 7b-d; Figure S10A in Additional file 2). By real-time RT-PCR, expression of mouse type I collagen mRNA was also suppressed in the secondary recipient liver transplanted with HLA-ABC-positive cells compared with the nontransplanted recipient livers (Figure S10B in
Additional file 2). On the other hand, the secondary transplantation of HLA-ABC-negative cells did not restore the hepatic function and fibrous tissue deposition in $\mathrm{CCl}_{4}$-injured livers (Fig. 7; Figures $\mathrm{S} 9$ and $\mathrm{S} 10$ in Additional file 2).

Moreover, by immunohistochemical and real-time PCR analyses, we demonstrated that secondary transplantation of HLA-ABC-positive cells significantly reduced the increased $\alpha \mathrm{SMA}$ expression in $\mathrm{CCl}_{4}$-injured liver tissues (Fig. 8a-c). Further real-time PCR assay demonstrated that the secondary transplantation of HLA-ABC-positive cells markedly inhibited the enhanced MMP2, MMP9, TIMP1, and TIMP2 mRNA expressions (Fig. 8d) in $\mathrm{CCl}_{4-}$ injured livers. On the other hand, the increased distribution of $\alpha$ SMA-positive cells and enhanced expression of $\alpha$ SMA, MMP2, MMP9, TIMP1, TIMP2, TGF- $\beta 1$, TNF $\alpha$, and IL-6 mRNAs were not recovered in $\mathrm{CCl}_{4}$-treated mice 

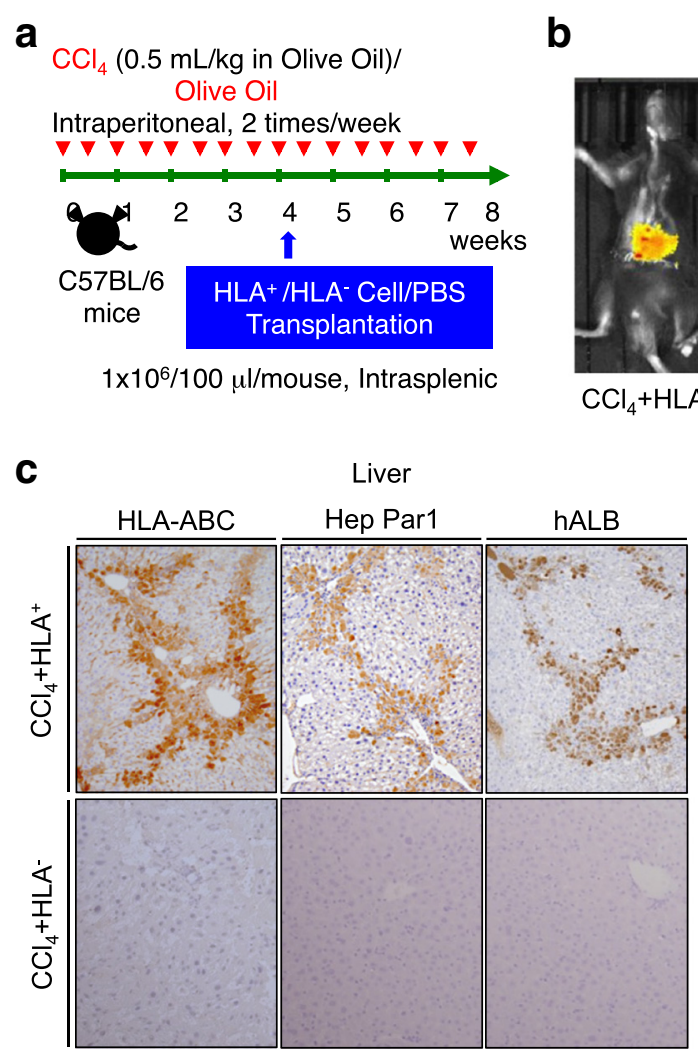

b
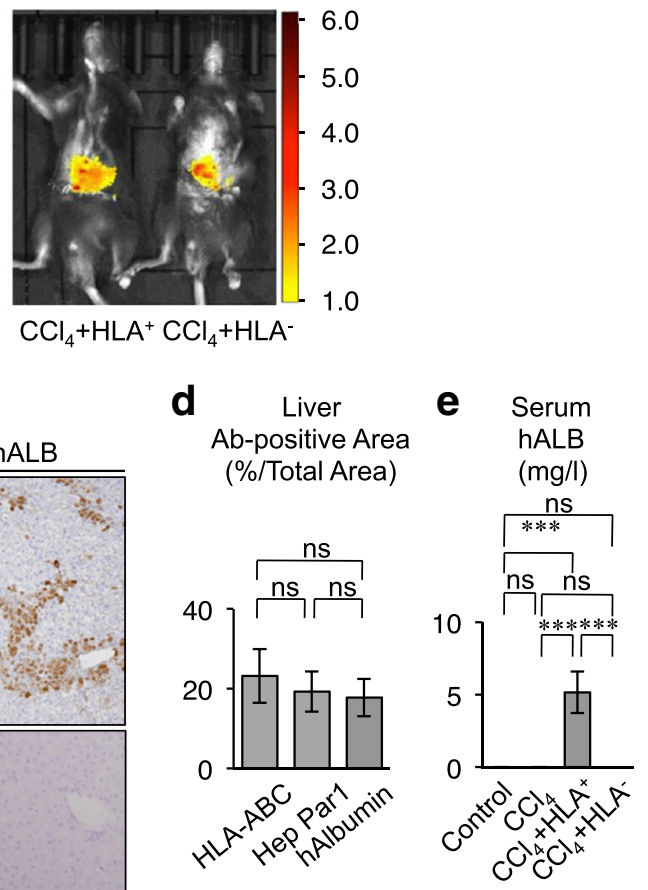

Fig. 6 Secondary transplanted primary HLA-ABC-positive cells home to $\mathrm{CCl}_{4}$-treated recipient livers. a Schema of secondary transplantation of

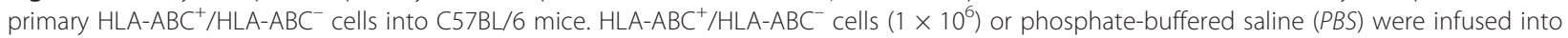
the mice that had intraperitoneally received $\mathrm{CCl}_{4}(0.5 \mathrm{ml} / \mathrm{kg})$ or olive oil only twice a week (red arrows). $\mathbf{b}$ In vivo monitoring of DiR-labeled HLA-ABC-positive $\left(H L A^{+}\right.$) and HLA-negative (HLA-) cells in $\mathrm{CCl}_{4}$-treated mice 24 hours (24h) after the infusion. $\mathbf{c}$, $\mathbf{d}$ Distribution of transplanted $\mathrm{HLA}^{+}$and $H L A^{-}$cells in the secondary recipient livers. Immunohistochemistry with anti-human HLA-ABC (HLA-ABC), anti-hepatocyte paraffin 1 (Hep Par1), or anti-human albumin (hALB) antibody. Representative images. c Counterstaining with hematoxylin. The human HLA-ABC, hepatocyte paraffin 1, or human albumin-positive area. $\mathbf{d}$ Immunopositive area shown as the ratio to the total area. e ELISA of human albumin ( $h A L B)$ in the recipient serum. c-e $n=5$ for all groups. ${ }^{* *} P<0.005$. $n$ s no significance. Graph bars show the mean \pm SD. Control, olive oil-injected group; $C C l_{4}$ $\mathrm{CCl}_{4}$-treated group; $\mathrm{CCl}_{4}+\mathrm{HLA}^{+}, \mathrm{HLA}^{+}$cell-transplanted $\mathrm{CCl}_{4}$-treated group; $\mathrm{CCl}_{4}+\mathrm{HLA}^{-}, \mathrm{HLA}^{-}$cell-transplanted $\mathrm{CCl}_{4}$-treated group. Ab antibody, $\mathrm{CCl}_{4}$ carbon tetrachloride, HepPar1 human hepatocyte specific HepParaffin 1 antigen, HLA human leukocyte antigen

that underwent secondary transplant with HLA-ABCnegative cells (Fig. 8). Taken together, these findings suggested that in vivo-generated hepatocyte-like cells in $\mathrm{CCl}_{4}$-injured livers with SHED transplantation worked functionally, at least partially, as human hepatocytes to display therapeutic efficacy for $\mathrm{CCl}_{4}$-induced liver fibrosis [38].

\section{Discussion}

Severe shortage of donor organs is a major challenge for liver transplantation [1]. Because of their unique capacities for homing and hepatic differentiation, MSCs and hematopoietic stem cells have been receiving attention as a source for cell therapy as an alternative to liver transplantation [39]. Transplantation of isolated mature hepatocytes has been used as an experimental therapy for liver disease in a limited number of cases. Recently,
100 cases of hepatocyte transplantation have been reported. Clinically, hepatocyte transplants express a proven efficiency, particularly in cases of metabolic liver disease where reversal or amelioration of the characteristic symptoms of the disease is easily quantified. However, no patients are completely corrected of a metabolic liver disease for a significant amount of time by hepatocyte transplantation alone [40]. MSC transplantation [12-14], as well as hematopoietic stem cell transplantation $[41,42]$, can successfully treat liver failure in animal models. MSCs exhibit a greater therapeutic efficacy with regard to homing and reducing fibrosis in comparison with hematopoietic stem cells in injured livers $[43,44]$. In the present study, we demonstrated that SHED transplantation improved $\mathrm{CCl}_{4}$-induced liver fibrosis and hepatic dysfunction via inertness of activated hepatic stellate cells and by replacement of damaged 


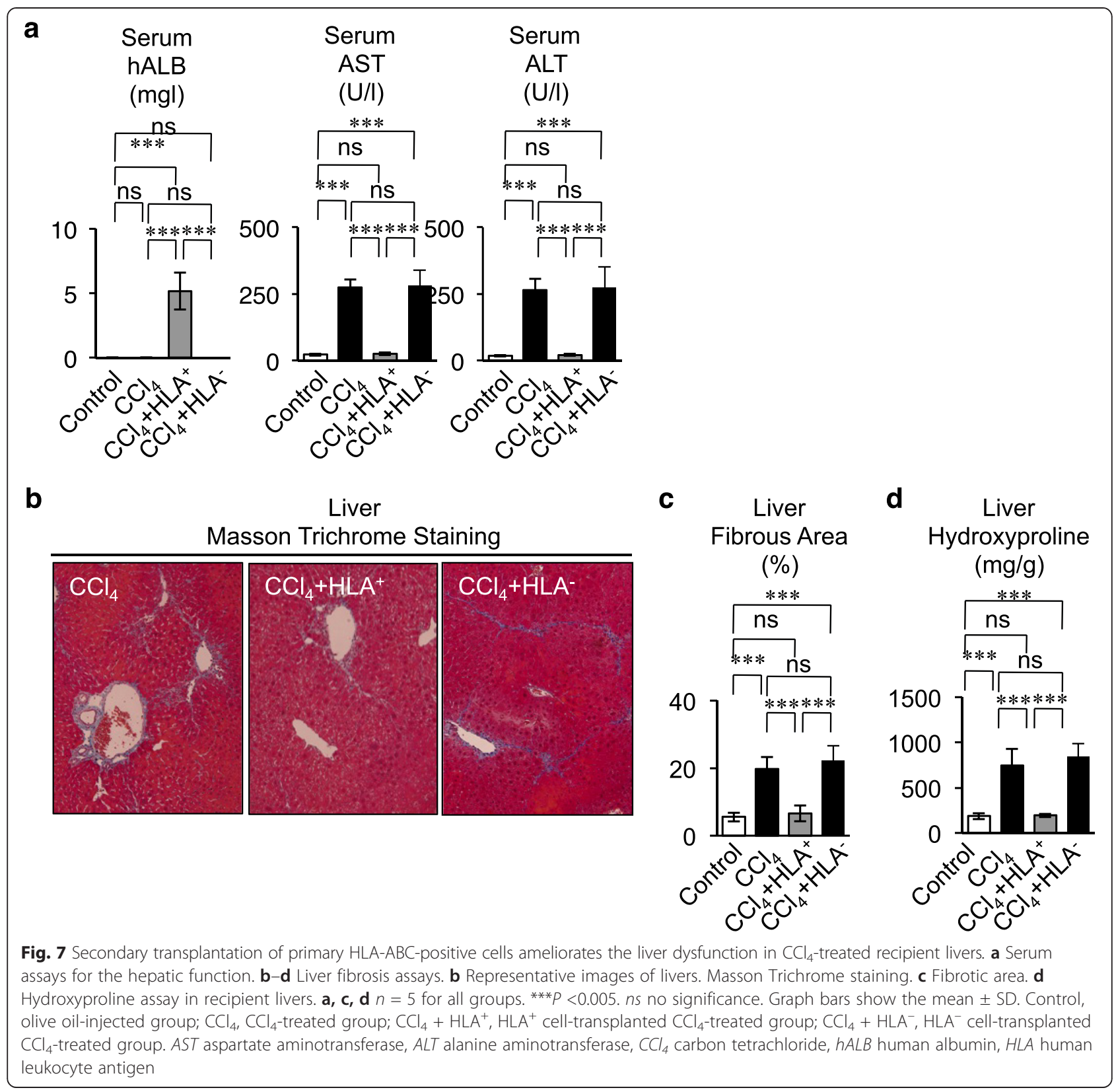

tissue with transplanted SHED-derived hepatocyte-like cells. These findings therefore suggest that SHED might be a promising MSC source for liver regeneration.

The present study demonstrated that SHED transplantation markedly suppressed not only the pathological activation of hepatic stellate cells, but also the excessive infiltration of Kupffer cells and T cells in $\mathrm{CCl}_{4}$-damaged mouse livers. Furthermore, SHED transplantation significantly reduced the enhanced production of fibrogenic and inflammatory factors, such as TGF- $\beta 1$, TNF $\alpha$, MMP2, MMP9, TIMP1, TIMP2, IL-6, and IL-17, and enhanced the expression of the anti-inflammatory factor IL-10 in $\mathrm{CCl}_{4}$-induced fibrous livers. Activated hepatic stellate cells contribute to liver fibrosis via abnormal production of MMP2, TIMP1, and TIMP2 through the secretion of various inflammatory cytokines from Kupffer cells and T cells [34, 35]. SHED can induce Tregs and suppress Th17 cells and monocytes/dendritic cells [16, 17]. Transplanted SHED might therefore suppress immune responses and promote anti-fibrotic regulation by affecting hepatic stellate cells, Kupffer cells, and $\mathrm{T}$ cells in $\mathrm{CCl}_{4}$-damaged mouse livers.

We speculate that a considerable number of transplanted SHED might be rejected immunologically owing to the present xenogeneic transplantation system and 


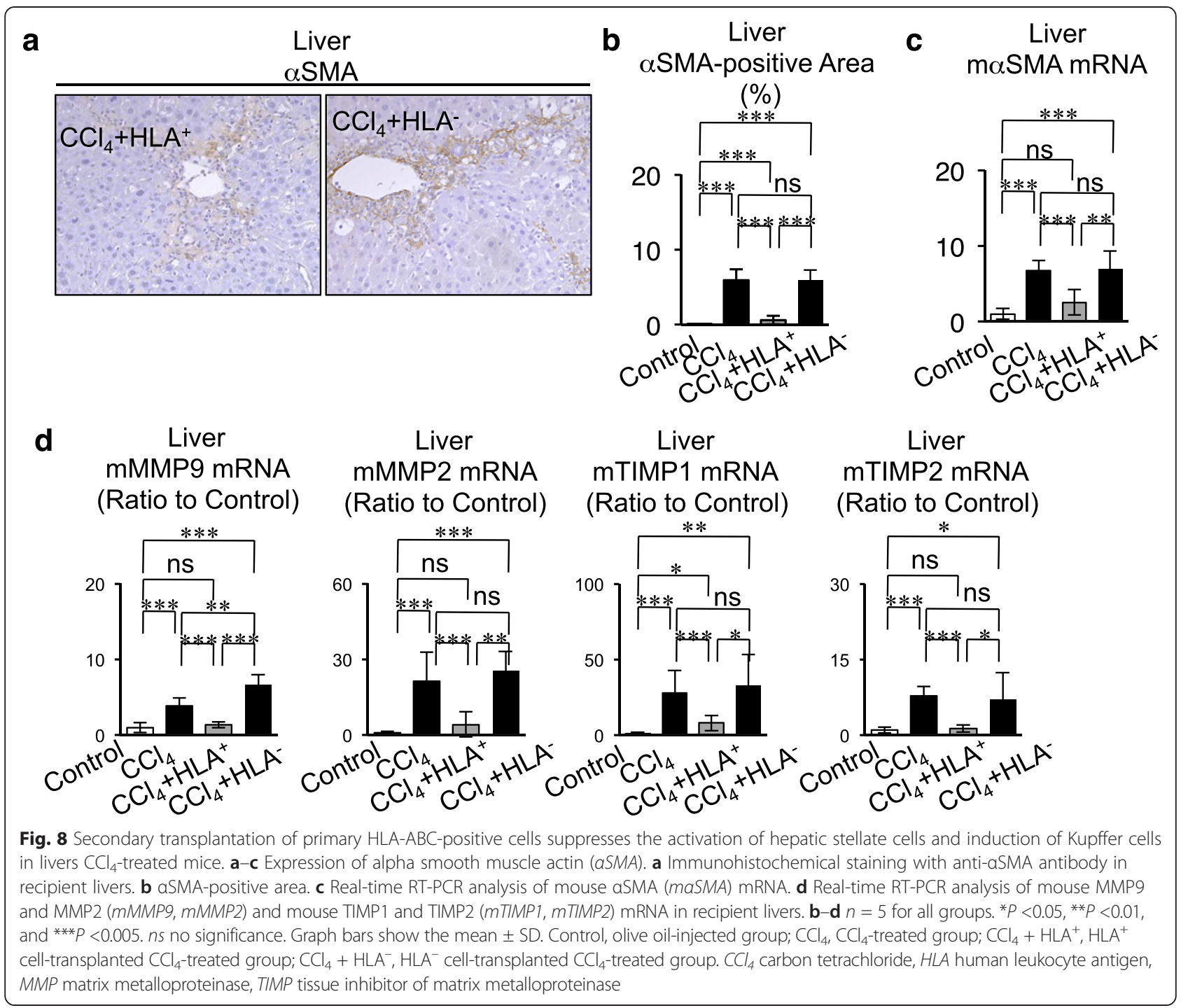

nonimmunosuppressive status in immunocompetent mice. We also consider a possibility that donor SHED and the differentiated hepatocytes, as well as recipient hepatocytes, might be damaged by chronic $\mathrm{CCl}_{4}$ stimuli. On the contrary, a result that donor SHED survived to differentiate into human hepatocytes in $\mathrm{CCl}_{4}$-injured liver tissues suggests that the donor cells maintained higher toxic resistance compared with recipient cells, and supports that donor SHED, at least partially, showed a tolerance to host immune response, even under nonimmunosuppressive condition, in immunocompetent mice. Furthermore, SHED transplantation did not induce any heavy infiltration of lymphocyte-like cells, as well as any change of structural components, in other tissues including the kidney, lung, and spleen of $\mathrm{CCl}_{4}$-treated mice. On the other hand, SHED transplantation suppressed the immune reaction in $\mathrm{CCl}_{4}$-treated mice. These findings support that donor
SHED did not cause any graft versus host disease-like reaction. Taken together, these findings suppose that SHED might exhibit safe immunology in the present xenogeneic transplantation system. Less HLA-DR expression and active immunomodulatory function of SHED may support a low immunogenicity and can acquire immune tolerance in vivo $[16,45]$. Further study will be necessary to confirm the immunological safety of SHED as a donor for allogenic transplantation, as well as autologous transplantation, for liver patients.

The liver is a site of hematopoiesis in the fetus, so bone marrow hematopoietic stem cells have been considered an origin for hepatocytes in adults [46, 47]. Transplanted hematopoietic stem cells fuse with host hepatic cells to repopulate the liver as functional hepatocytes $[36,37]$. On the other hand, a nonfusion origin of human hepatocytes was proposed in mouse liver 
transplanted with human hematopoietic cells [48-50]. Engrafted bone marrow MSCs directly transdifferentiated into hepatocytes without cell fusion in rat livers [24]. Therefore, whether donor human cells fuse with recipient hepatic cells in mouse liver has not yet been fully understood. The presented three different approaches with a cell sorting technique of MHC class I antigen HLA-ABC-expressed human cells from the recipient mouse liver were carried out to evaluate the possibility of fusion between donor human MSCs and recipient murine hepatocytes. By flow cytometric analysis using human and mouse specific antibodies against MHC class I antigen, cell fusion of the donor cells and recipient cells was excluded. PCR analysis using human and mouse specific primers also omits the possibility of cell fusion. In a further secondary transplant assay, HLA-ABC-negative cells have in vivo differentiation capacity into human hepatocytes. These results indicate that donor-derived human hepatocytes have only human genetic and immunological properties, suggesting that cell fusion of donor SHED and recipient hepatocytes in the hepatogenic process may be a rare or nonexistent phenomenon in recipient $\mathrm{CCl}_{4}$-injured mice. From another point of view, cell fusion between recipient hepatocytes and hematopoietic stem cells might lead to genetic instability and formation of cancer stem cells [51]. Human MSCs exhibit a low tumorigenic potential in vivo [52] and in vitro [53]. The present findings indicate that SHED may provide an attractive and safe source for stem cell-based liver regeneration. However, a long-term in vivo experiment will be necessary to assess the safety and tumorigenic risk(s) after SHED transplantation in damaged livers.

The present immunohistochemical findings suggest that intrasplenically infused donor SHED are transported into recipient liver through the portal vein system via the splenic vein, and penetrated into $\mathrm{CCl}_{4}$-damaged fibrous area via the interlobular portal veins. However, the mechanism underlying in vivo homing and hepatic potential of transplanted MSCs, including SHED, remains unclear. In vivo homing and hepatic potential of MSCs might be regulated by a microenvironment of injured liver tissues. Liver contributes to a niche for hematopoietic stem cells in the fetus [54] and in patients with osteomyelofibrosis [55]. Hepatic stellate cells support hematopoiesis in fetal livers [56], and activated hepatic stellate cells release a factor associated with stem cell homing and migration, C-X-C motif chemokine 12 [57], and a factor promoting hepatocyte proliferation and differentiation, HGF [58]. In addition, hepatic stellate cells modulate a hepatogenic potential of bone marrow MSCs [59]. These previous studies suggest that activated hepatic stellate cells might function as a niche to modulate the homing and hepatic differentiation of transplanted MSCs. Further studies will be necessary to elucidate cellular and molecular mechanism(s) responsible for in vivo homing and hepatic potential of transplanted MSCs, including SHED.

In this study, purified HLA-ABC-positive cells from liver tissue of SHED-transplanted $\mathrm{CCl}_{4}$-treated mice confirmed the expression of several characteristics as human hepatocyte-like cells. The present secondary transplantation into $\mathrm{CCl}_{4}$-treated mice analysis demonstrates that purified HLA-ABC-positive cells express a homing capacity and a treatment efficacy in $\mathrm{CCl}_{4}$-injured mice, suggesting that in vivo-converted SHEDderived hepatocytes may function as human hepatocytes. Chimeric human livers with more than $90 \%$ human hepatocytes are successfully developed in murine models $[60,61]$. A recently reported novel tissue engineering approach generated a transplantable recellularized liver graft with human hepatocytes and MSCs using xenogeneic decellularized livers [62, 63]. The present in vivo serial transplantation assay demonstrated that SHED-derived direct-converted hepatocytes exhibit chimerism and therapeutic effect in $\mathrm{CCl}_{4}$-damaged mouse livers. These results suggest that in vivogenerated human hepatocyte-like cells derived from donor SHED may provide an alternative source for banking of human hepatocytes and development of human chimeric livers in vivo and ex vivo.

\section{Conclusion}

In summary, this report provides a foundation for SHED-based liver regenerative medicine. Further studies will be required to elucidate whether this practical and unique approach can be applied clinically for patients with liver disorders, such as liver fibrosis, metabolic diseases, or some coagulopathies.

\section{Additional files}

Additional file 1: Presents supplementary methods. (DOC $91 \mathrm{~kb}$ )

Additional file 2: Figure S1. Showing characterization of SHED, Figure S2 showing CFSE-labeled cell tracing of donor SHED 1 day after transplantation, Figure S3 showing histological and immunohistochemical analyses of the kidney, lung, and spleen of $\mathrm{CCl}_{4}$-treated mice with splenic SHED transplantation, Figure S4 showing immunohistochemical negative control analysis, Figure S5 showing immunohistochemical analysis of human liver, Figure S6 showing transplantation of human gingival fibroblasts into $\mathrm{CCl}_{4}$-treated mice, Figure S7 showing the schema for cell sorting of human cells from recipient liver tissues of $\mathrm{CCl}_{4}$-treated mice transplanted with SHED, Figure S8 showing human HLA-ABC, hepatocyte paraffin1 (Hep Par1), or human albumin (hALB) antibody-positive area in the recipient liver tissues of secondary transplant CCL-treated mice, Figure $\mathbf{5 9}$ showing serum assays for the hepatic function in secondary transplant CCl4-treated mice, and Figure S10 showing fibrous assay in recipient livers of secondary transplant CCl4-treated mice. (PDF 1386 kb)

Additional file 3: Table S1. Presenting the TaqMan primers and probes used for mouse genes used in real-time PCR, and Table S2 presenting the primer pairs used for human and mouse genes for genomic PCR and RT-PCR. (DOC 65 kb) 


\section{Abbreviations}

ALP: Alkaline phosphatase; ALT: Alanine aminotransferase:

APC: Allophycocyanin; AST: Aspartate aminotransferase; $\mathrm{CCl}_{4}$ : Carbon tetrachloride; CFSE: Carboxyfluorescein diacetate succinimidyl ester; DiR: 1,1-Dioctadecyl-3,3,3,3-tetramethylindotricarbocyanine iodide; EGF: Epidermal growth factor; ELISA: Enzyme-linked immunosorbent assay; FGF2: Fibroblast growth factor 2; GAPDH: Glyceraldehyde 3-phosphate dehydrogenase; HGF: Hepatocyte growth factor; HLA: Human leukocyte antigen; IL: Interleukin; MHC: Major histocompatibility complex; MMP: Matrix metalloproteinase; MSC: Mesenchymal stem cell; NIR: Near infrared; P3: Passage 3; PBS: Phosphate-buffered saline; PE: Phycoerythrin; SD: Standard deviation; SHED: Stem cells from human exfoliated deciduous teeth; TGF- $\beta 1$ : Transforming growth factor $\beta 1$; Th17: Interleukin-17-producing helper T; TIMP: Tissue inhibitor of metalloproteinase; TNFa: Tumor necrosis factor alpha; Tregs: Regulatory T cells; UDP: Uridine 5'-diphosphate; UDP: Uridine 5'-diphosphate: aSMA: Alpha smooth muscle actin.

\section{Competing interests}

The authors declare that they have no competing interest.

\section{Authors' contributions}

TY carried out conception and design of the study, generation, collection and assembly of data, interpretation of data, statistical analysis, and drafting of the manuscript. FSA carried out generation, collection and assembly of data, and interpretation of data. RY, HY, JKF, YY, KY, MH, TM, and RA participated in interpretation of data. KI, SO, SS, and KN participated in conception and design of the study, interpretation of data, and study supervision. TT participated in conception and design of the study, interpretation of data, drafting of the manuscript, critical revision of the manuscript for important intellectual content, and study supervision. All authors read and approved the final manuscript.

\section{Acknowledgements}

The authors are very thankful to Mr Brian Quinn for his English assistance with writing. They also appreciate Ms Tomoko Yamazaki (Department of Pediatric Surgery, Kyushu University Graduate School of Medical Sciences) for her excellent assistance and Dr Soichiro Sonoda (Department of Molecular Cell Biology and Oral Anatomy, Kyushu University Graduate School of Dental Science) for his histological assistance and writing support during this study. This work was supported by grants from the Japan Society for the Promotion of Science, including Grant-in-Aid for Scientific Research (A) (grant number 25253094 to TT), Grant-in-Aid for Scientific Research (B) (grant number 25293405 to TY), and Grant-in-Aid for Challenging Exploratory Research Project (grant numbers 23659618 and 25670744 to $T$ and grant number 24659815 to TY), from the Ministry of Education, Culture, Sports, Science and Technology of Japan for Translational Research Grant of Center for Clinical and Translational Research Seeds B3 to TT, and from the Ministry of Health, Labor and Welfare for Research on Rare and Intractable Diseases (grant number H26-040) to TT. This research is also partially supported by the Translational Research Network Program from Japan Agency for Medical Research and Development, AMED. The authors appreciate Professor Fusanori Nishimura (Department of Periodontology, Kyushu University Graduate School of Dental Science) for his technical assistance through the program for the Promotion of Strategic International Research Network accelerating Brain Rotation (S2605) by the Japan Society for the Promotion of Science.

\section{Author details}

'Department of Molecular Cell Biology and Oral Anatomy, Kyushu University Graduate School of Dental Science, 3-1-1 Maidashi, Higashi-ku, Fukuoka 812-8582, Japan. ${ }^{2}$ Department of Pediatric Surgery, Kyushu University Graduate School of Medical Sciences, 3-1-1 Maidashi, Higashi-ku, Fukuoka 812-8582, Japan. ${ }^{3}$ Department of Pediatric Dentistry, Kyushu University Graduate School of Dental Science, 3-1-1 Maidashi, Higashi-ku, Fukuoka 812-8582, Japan. ${ }^{4}$ Department of Pediatrics, Kyushu University Graduate School of Medical Sciences, 3-1-1 Maidashi, Higashi-ku, Fukuoka 812-8582, Japan. ${ }^{5}$ Department of Pediatrics, Faculty of Medicine, Oita University, 1-1 Idaigaoka, Hazama-cho, Yuhuin 879-5593, Japan. 'Department of Pediatrics, Faculty of Medicine and Health Sciences, Yamaguchi University, 1-1-1 Minami Ogushi, Ube 755-8505, Japan. ${ }^{7}$ Department Anatomy and Cell Biology, School of Dental Medicine, University of Pennsylvania, 240 South 40th Street, Philadelphia, PA 19104-6030, USA.
Received: 16 April 2015 Revised: 2 July 2015 Accepted: 12 August 2015 Published online: 10 September 2015

\section{References}

1. Murray KF, Carithers Jr RL. AASLD practice guidelines: evaluation of the patient for liver transplantation. Hepatology. 2005;41:1407-32.

2. Horslen SP, McCowan TC, Goertzen TC, Warkentin PI, Cai HB, Strom SC, et al. Isolated hepatocyte transplantation in an infant with a severe urea cycle disorder. Pediatrics. 2003;111:1262-7.

3. Ishikawa T, Banas A, Teratani T, Iwaguro H, Ochiya T. Regenerative cells for transplantation in hepatic failure. Cell Transplant. 2012;21:387-99.

4. Petersen BE, Bowen WC, Patrene KD, Mars WM, Sullivan AK, Murase N, et al. Bone marrow as a potential source of hepatic oval cells. Science. 1999;284:1168-70.

5. Friedenstein AJ, Deriglasova UF, Kulagina NN, Panasuk AF, Rudakowa SF, Luriá EA, et al. Precursors for fibroblasts in different populations of hematopoietic cells as detected by the in vitro colony assay method. Exp Hematol. 1974;22:83-92.

6. Katz AJ, Tholpady A, Tholpady SS, Shang H, Ogle RC. Cell surface and transcriptional characterization of human adipose-derived adherent stromal (hADAS) cells. Stem Cells. 2005:23:412-23.

7. Mareschi K, Biasin E, Piacibello W, Aglietta M, Madon E, Fagioli F. Isolation of human mesenchymal stem cells: bone marrow versus umbilical cord blood. Haematologica. 2001:86:1099-100

8. Peng SY, Chou CJ, Cheng PJ, Ko IC, Kao YJ, Chen YH, et al. Therapeutic potential of amniotic-fluid-derived stem cells on liver fibrosis model in mice. Taiwan J Obstet Gynecol. 2014;53:151-7.

9. Gronthos S, Mankani M, Brahim J, Robey PG, Shi S. Postnatal human dental pulp stem cells (DPSCs) in vitro and in vivo. Proc Natl Acad Sci USA. 2000;97:13625-30.

10. Uccelli A, Pistoia V, Moretta L. Mesenchymal stem cells: a new strategy for immunosuppression? Trends Immunol. 2007;28:219-26.

11. Caplan Al. Adult mesenchymal stem cells for tissue engineering versus regenerative medicine. J Cell Physiol. 2007;213:341-7.

12. Mohamadnejad M, Alimoghaddam K, Mohyeddin-Bonab M, Bagheri M, Bashtar $\mathrm{M}$, Ghanaati $\mathrm{H}$, et al. Phase 1 trial of autologous bone marrow mesenchymal stem cell transplantation in patients with decompensated liver cirrhosis. Arch Iran Med. 2007;10:459-66.

13. Kharaziha P, Hellström PM, Noorinayer B, Farzaneh F, Aghajani K, Jafari F, et al. Improvement of liver function in liver cirrhosis patients after autologous mesenchymal stem cell injection: a phase I-II clinical trial. Eur J Gastroenterol Hepatol. 2009;21:1199-205.

14. El-Ansary M, Abdel-Aziz I, Mogawer S, Abdel-Hamid S, Hammam O, Teaema $S$, et al. Phase II trial: undifferentiated versus differentiated autologous mesenchymal stem cells transplantation in Egyptian patients with HCV induced liver cirrhosis. Stem Cell Rev. 2012;8:972-81.

15. Miura M, Gronthos $S$, Zhao M, Lu B, Fisher LW, Robey PG, et al. SHED: stem cells from human exfoliated deciduous teeth. Proc Natl Acad Sci USA. 2003;100:5807-12.

16. Yamaza T, Kentaro A, Chen C, Liu Y, Shi Y, Gronthos S, et al. Immunomodulatory properties of stem cells from human exfoliated deciduous teeth. Stem Cell Res Ther. 2010;1:5.

17. Silva Fde S, Ramos RN, Almeida DC, Bassi EJ, Gonzales RP, Miyagi SP, et al. Mesenchymal stem cells derived from human exfoliated deciduous teeth (SHEDs) induce immune modulatory profile in monocyte-derived dendritic cells. PLoS One. 2014;9:e98050.

18. Seo BM, Sonoyama W, Yamaza T, Coppe C, Kikuiri T, Akiyama K, et al. SHED repair critical-size calvarial defects in immunocompromised mice. Oral Dis. 2008;14:428-34.

19. Zheng Y, Liu Y, Zhang CM, Zhang HY, Li WH, Shi S, et al. Stem cells from deciduous tooth repair mandibular defect in swine. J Dent Res. 2009;88:249-54.

20. Wang J, Wang $X$, Sun Z, Wang $X$, Yang H, Shi $S$, et al. Stem cells from human-exfoliated deciduous teeth can differentiate into dopaminergic neuron-like cells. Stem Cells Dev. 2010;19:1375-83.

21. Sakai K, Yamamoto A, Matsubara K, Nakamura S, Naruse M, Yamagata M, et al. Human dental pulp-derived stem cells promote locomotor recovery after complete transection of the rat spinal cord by multiple neuroregenerative mechanisms. J Clin Invest. 2012;122:80-90.

22. Kanafi MM, Ramesh A, Gupta PK, Bhonde RR. Influence of hypoxia, high glucose, and low serum on the growth kinetics of mesenchymal stem cells from deciduous and permanent teeth. Cells Tissues Organs. 2013;198:198-208 
23. Ma L, Makino Y, Yamaza H, Akiyama K, Hoshino Y, Song G, et al. Cryopreserved dental pulp tissues of exfoliated deciduous teeth is a feasible stem cell resource for regenerative medicine. PLoS One. 2012;7:e51777.

24. Sato $Y$, Araki H, Kato J, Nakamura K, Kawano Y, Kobune M, et al. Human mesenchymal stem cells xenografted directly to rat liver are differentiated into human hepatocytes without fusion. Blood. 2005;106:756-63.

25. Seo MJ, Suh SY, Bae YC, Jung JS. Differentiation of human adipose stromal cells into hepatic lineage in vitro and in vivo. Biochem Biophys Res Commun. 2005:328:258-64

26. Jung KH, Shin HP, Lee S, Lim YJ, Hwang SH, Han H, et al. Effect of human umbilical cord blood-derived mesenchymal stem cells in a cirrhotic rat model. Liver Int. 2009;29:898-909.

27. Bishi DK, Mathapati S, Venugopal JR, Guhathakurta S, Cherian KM, Ramakrishna S, et al. Trans-differentiation of human mesenchymal stem cells generates functional hepatospheres on poly(L-lactic acid)-copoly( $\varepsilon$-caprolactone)/collagen nanofibrous scaffolds. J Mater Chem B. 2013;1:3972-84

28. Bishi DK, Mathapati S, Cherian KM, Guhathakurta S, Verma RS. In vitro hepatic trans-differentiation of human mesenchymal stem cells using sera from congestive/ischemic liver during cardiac failure. PLoS One. 2014;9:e92397.

29. Arora V, Arora P, Munshi AK. Banking stem cells from human exfoliated deciduous teeth (SHED): saving for the future. J Clin Pediatr Dent. 2009:33:289-94.

30. Ji EH, Song JS, Kim SO, Jeon M, Choi BJ, Lee JH. Viability of pulp stromal cells in cryopreserved deciduous teeth. Cell Tissue Bank. 2014;15:67-74.

31. Ishkitiev N, Yaegaki K, Calenic B, Nakahara T, Ishikawa H, Mitiev V, et al. Deciduous and permanent dental pulp mesenchymal cells acquire hepatic morphologic and functional features in vitro. J Endod. 2010;36:469-74.

32. Dominici M, Le Blanc K, Mueller I, Slaper-Cortenbach I, Marini F, Krause D, et al. Minimal criteria for defining multipotent mesenchymal stromal cells. The International Society for Cellular Therapy position statement. Cytotherapy. 2006;8:315-7.

33. Ishak K, Baptista A, Bianchi L, Callea F, De Groote J, Gudat F, et al. Histological grading and staging of chronic hepatitis. J Hepatol. 1995;22:696-9.

34. Moreira RK. Hepatic Stellate Cells and liver fibrosis. Arch Pathol Lab Med. 2007;131:1728-34

35. Meng F, Wang K, Aoyama T, Grivennikov SI, Paik Y, Scholten D, et al. Interleukin-17 signaling in inflammatory, Kupffer cells, and hepatic stellate cells exacerbates liver fibrosis in mice. Gastroenterology. 2012;143:765-76.

36. Wang $X$, Willenbring $H$, Akkari $Y$, Torimaru $Y$, Foster $M, A l-D h a l i m y ~ M$, et al. Cell fusion is the principal source of bone-marrow-derived hepatocytes. Nature. 2003;422:897-901.

37. Vassilopoulos G, Wang PR, Russell DW. Transplanted bone marrow regenerates liver by cell fusion. Nature. 2003;422:901-4.

38. Asgari S, Moslem M, Bagheri-Lankarani K, Pournasr B, Miryounesi M, Baharvand $\mathrm{H}$. Differentiation and transplantation of human induced pluripotent stem cell-derived hepatocyte-like cells. Stem Cell Rev. 2013;9:493-504.

39. Kakinuma S, Nakauchi H, Watanabe M. Hepatic stem/progenitor cells and stem-cell transplantation for the treatment of liver disease. J Gastroentel. 2009:44:167-72.

40. Hansel MC, Gramignoli R, Skvorak KJ, Marongiu F, Bkake W, Davila J, et al. The history and use of human hepatocytes for the treatment of liver diseases: the first 100 patients. Curr Protoc Toxicol. 2014;62:14. 12.1-23.

41. Terai S, Ishikawa T, Omori K, Aoyama K, Marumoto Y, Urata Y, et al. Improved liver function in patients with liver cirrhosis after autologous bone marrow cell infusion therapy. Stem Cells. 2006;24:2292-8.

42. Salama H, Zekri AR, Zern M, Bahnassy A, Loutfy S, Shalaby S, et al. Autologous hematopoietic stem cell transplantation in 48 patients with end-stage chronic liver diseases. Cell Transplant. 2010;19:1475-86.

43. Pulavendran S, Vignesh J, Rose C. Differential anti-inflammatory and anti-fibrotic activity of transplanted mesenchymal vs. hematopoietic stem cells in carbon tetrachloride-induced liver injury in mice. Int Immunopharmacol. 2010;10:513-9.

44. Li Q, Zhou X, Shi Y, Li J, Zheng L, Cui L, et al. In vivo tracking and comparison of the therapeutic effects of MSCs and HSCs for liver injury. PLoS One. 2013;8:e62363.

45. Bernardi L, Luisi SB, Fernandes R, Dalberto TP, Valentim L, Bogo Chies JA, et al. The isolation of stem cells from human deciduous teeth pulp is related to the physiological process of resorption. J Endod. 2011;37:973-9.
46. Alison MR, Poulsom R, Jeffery R, Dhillon AP, Quaglia A, Jacob J, et al. Hepatocytes from non-hepatic adult stem cells. Nature. 2000;406:257.

47. Theise ND, Nimmakayalu M, Gardner R, Illei PB, Morgan G, Teperman L, et al. Liver from bone marrow in humans. Hepatology. 2000;32:11-6.

48. Jang YY, Collector MI, Baylin SB, Diehl AM, Sharkis SJ. Hematopoietic stem cells convert into liver cells within days without fusion. Nat Cell Biol. 2004;6:532-9.

49. Newsome PN, Johannessen I, Boyle S, Dalakas E, McAulay KA, Samuel K, et al. Human cord blood-derived cells can differentiate into hepatocytes in the mouse liver with no evidence of cellular fusion. Gastroenterology. 2003;124:1891-900.

50. Ishikawa F, Drake CJ, Yang S, Fleming P, Minamiguchi H, Visconti RP, et al. Transplanted human cord blood cells give rise to hepatocytes in engrafted mice. Ann N Y Acad Sci. 2003;996:174-85.

51. Bjerkvig R, Tysnes BB, Aboody KS, Najbauer J, Terzis AJ. Opinion: the origin of the cancer stem cell: current controversies and new insights. Nat Rev Cancer. 2005:5:899-904.

52. Miura M, Miura Y, Padilla-Nash HM, Molinolo AA, Fu B, Patel V, et al. Accumulated chromosomal instability in murine bone marrow mesenchymal stem cells leads to malignant transformation. Stem Cells. 2006:24:1095-103.

53. Kim J, Kang JW, Park JH, Choi Y, Choi KS, Park KD, et al. Biological characterization of long-term cultured human mesenchymal stem cells. Arch Pharm Res. 2009:32:117-26.

54. Jordan CT, McKearn JP, Lemischka IR. Cellular and developmental properties of fetal hematopoietic stem cells. Cell. 1990;61:953-63.

55. Kim CH. Homeostatic and pathogenic extramedullary hematopoiesis. J Blood Med. 2010;1:13-9.

56. Kordes C, Sawitza I, Götze S, Häussinger D. Hepatic stellate cells support hematopoiesis and are liver-resident mesenchymal stem cells. Cell Physiol Biochem. 2013;31:290-304.

57. Hong F, Tuyama A, Lee TF, Loke J, Agarwal R, Cheng X, et al. Hepatic stellate cells express functional CXCR4: role in stromal cell-derived factor-1alpha-mediated stellate cell activation. Hepatology. 2009:49:2055-67.

58. Ishikawa T, Factor VM, Marquardt JU, Raggi C, Seo D, Kitade M, et al. Hepatocyte growth factor/c-met signaling is required for stem-cell-mediated liver regeneration in mice. Hepatology. 2012;55:1215-26.

59. Deng $X$, Chen YX, Zhang X, Zhang JP, Yin C, Yue HY, et al. Hepatic stellate cells modulate the differentiation of bone marrow mesenchymal stem cells into hepatocyte-like cells. J Cell Physiol. 2008;217:138-44.

60. Azuma H, Paulk N, Ranade A, Dorrell C, Al-Dhalimy M, Ellis E, et al. Robust expansion of human hepatocytes in $\mathrm{Fah}^{-/-} / \mathrm{Rag}^{-/-} / \mathrm{II} 2 \mathrm{rg}^{-1-}$ mice. Nat Biotechnol. 2007;25:903-10.

61. Hasegawa M, Kawai K, Mitsui T, Taniguchi K, Monnai M, Wakui M, et al. The reconstituted 'humanized liver' in TK-NOG mice is mature and functional. Biochem Biophys Res Commun. 2011;405:405-10.

62. Uygun BE, Soto-Gutierrez A, Yagi H, Izamis ML, Guzzardi MA, Shulman C, et al, Organ reengineering through development of a transplantable recellularized liver graft using decellularized liver matrix. Nat Med. 2010;16:814-20.

63. Ji R, Zhang N, You N, Li Q, Liu W, Jiang N, et al. The differentiation of MSCs into functional hepatocyte-like cells in a liver biomatrix scaffold and their transplantation into liver-fibrotic mice. Biomaterials. 2012;33:8995-9008. 